\title{
When feasibility does not mean clinical success: Early failure of a percutaneous tricuspid reduction system
}

Thierry Carrel, MD, and Balthasar Eberle, MD, Bern, Switzerland

\author{
From the Departments of Cardiovascular Surgery and Anaesthesiology and Pain Medicine, Inselspital, Bern Uni- \\ versity Hospital, University of Bern, Bern, Switzerland. \\ Disclosures: Authors have nothing to disclose with regard to commercial support. \\ Received for publication May 8, 2019; revisions received June 11, 2019; accepted for publication June 17, 2019; \\ available ahead of print Aug 27, 2019. \\ Address for reprints: Thierry Carrel, MD, Department of Cardiovascular Surgery, Inselspital, Bern University \\ Hospital, Freiburgstrasse CH-3010, Bern, Switzerland (E-mail: thierry.carrel@insel.ch). \\ J Thorac Cardiovasc Surg 2020;159:e109-11 \\ $0022-5223 / \$ 36.00$ \\ Copyright (C) 2019 by The American Association for Thoracic Surgery \\ https://doi.org/10.1016/j.jtcvs.2019.06.066
}

Video clip is available online.

The 4Tech TriCinch Transcatheter Tricuspid Valve Repair System (4Tech Cardio Ireland Ltd, Galway, Ireland) has been designed to allow treatment of functional tricuspid regurgitation through transfemoral venous access. In summary, an anchor is placed onto the tricuspid valve annulus through transfemoral venous access. Thereafter a largediameter stent for the inferior vena cava is connected to this tricuspid anchor. Finally, tension is applied on the implant to reduce the septolateral distance substantially and remodel the anteroposterior annulus, while the stent is deployed into the inferior vena cava to maintain tension. Previous reports have shown feasibility of single and double device implantation; however, midterm clinical results are lacking. ${ }^{1,2}$

\section{CLINICAL CASE}

A 77-year-old female patient was referred to another tertiary center because of symptomatic severe functional tricuspid valve regurgitation. The main echocardiographic finding was severe annular dilatation (septolateral dimension, $51 \mathrm{~mm}$ ) with lack of leaflet coaptation. There was permanent atrial fibrillation. Systolic left ventricular function was normal (left ventricular ejection fraction, 55\%), with only minimal mitral regurgitation and no pulmonary hypertension.

The patient underwent a TriCinch implantation procedure under a compassionate use exemption. Two TriCinch devices were ultimately necessary, because of persistent severe regurgitation after implantation of the first device. Both devices provided a reduction in septolateral dimension from 51 to $47 \mathrm{~mm}$. Surprisingly, this double TriCinch

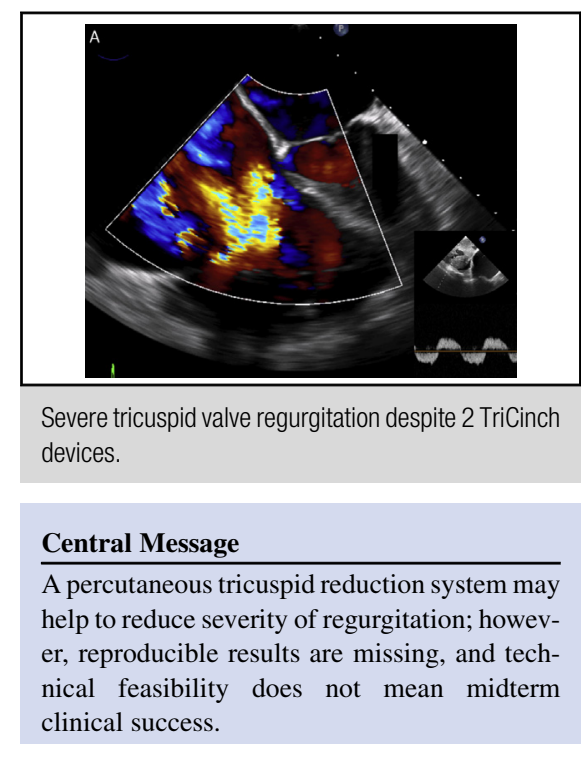

See Commentary on page e113.

implantation was described as a success, although severe residual regurgitation persisted on postoperative echocardiography. Clinical symptoms had improved slightly after 1 month. Brain natriuretic peptide decreased from 489 to $198 \mathrm{pg} / \mathrm{mL}$. The patient was rehospitalized several times, however, because of cardiac decompensation, liver congestion, and peripheral edema with venous ulcers.

Percutaneous tricuspid valve implantation was recommended in the same center, but the patient refused because of her bad experience with the TriCinch. Eighteen months after the procedure, severe cardiac decompensation occurred (brain natriuretic peptide, $1850 \mathrm{pg} / \mathrm{mL}$; high transaminases). The patient required inotropic support and artificial ventilation. Atrioventricular block III developed, and she received a temporary pacemaker. The patient was transferred to our institution. Severe tricuspid regurgitation (Figure 1,A) with complete ventricularization of the right atrial pressure tracing was shown. The TriCinch devices could not be visualized within the right atrium. Angiography showed complete dislocation of both anchors together with both tethers into the inferior vena cava (Figure 1,B), Conventional tricuspid valve replacement with a 33-mm tissue valve was performed through a sternotomy on the beating heart with cardiopulmonary bypass, and an epicardial DDD pacemaker was implanted. No TriCinch material was encountered in the right atrium. 


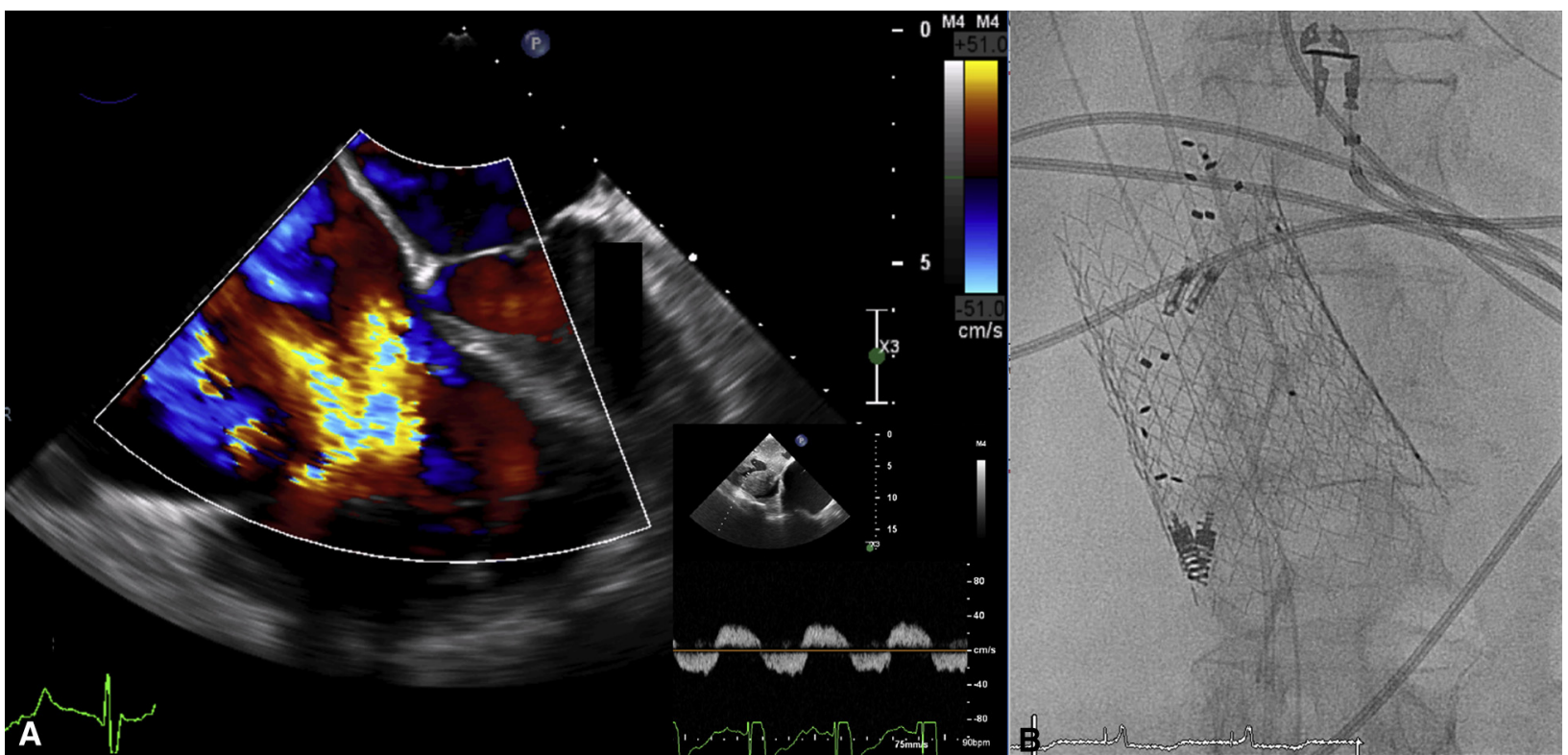

FIGURE 1. Postinterventional transesophageal echocardiographic and angiographic findings. Severe tricuspid regurgitation 18 months after double TriCinch (4Tech Cardio Ireland Ltd, Galway, Ireland) procedure on (A) transesophageal echocardiography with (insert) holosystolic hepatic venous flow reversal. Caval stents (B) of the TriCinch-in-TriCinch assembly with both anchors and tethers dislocated into the inferior caval vein away from the tricuspid annulus.

Echocardiography at the end of the procedure showed a normal function of the bioprosthesis, with moderately impaired right ventricular function (Figure 2, A). After hemodynamic stabilization, the sternum was closed on postoperative day 3 . The patient was discharged after 3 weeks to a rehabilitation clinic.

One year later, the patient's condition has considerably improved under a mild regimen of heart failure medication, including diuretics and low-dose nebivolol. At last followup, the patient was in New York Heart Association functional class I to II. All signs of right-sided heart failure have resolved, and echocardiography shows a normal functioning tissue valve with a mean gradient of $2.5 \mathrm{~mm} \mathrm{Hg}$ and a normalized right ventricular function.

\section{DISCUSSION}

Transcatheter technologies represent an important advance for older and high-risk patients, because they are less invasive. For treatment of atrioventricular valve regurgitation, several options are available or in development,

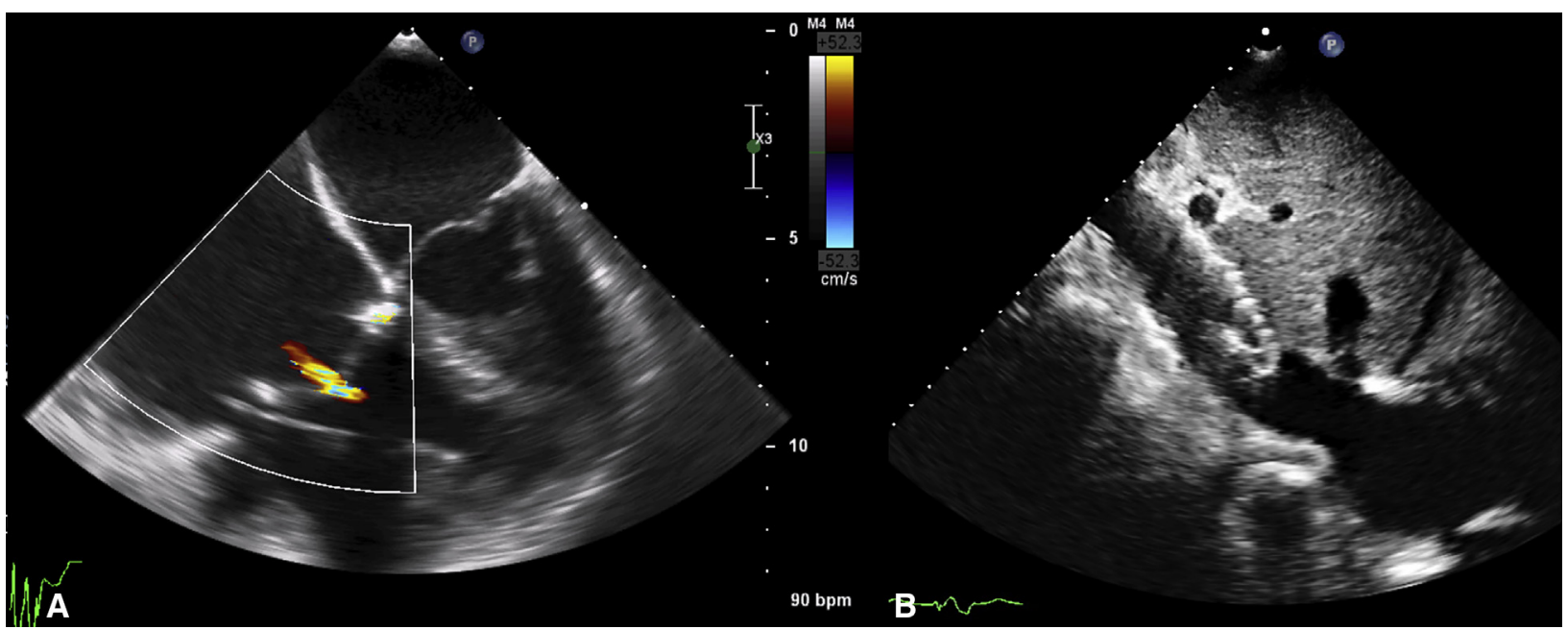

FIGURE 2. Postoperative echocardiography after conventional tricuspid valve replacement. Minimal transvalvular regurgitation (A) after surgical tricuspid valve replacement (Perimount Magna Ease $33 \mathrm{~mm}$ tissue valve; Edwards Lifesciences, Irvine, Calif). TriCinch (4Tech Cardio Ireland Ltd, Galway, Ireland) stents (B) remaining in the inferior vena cava. 


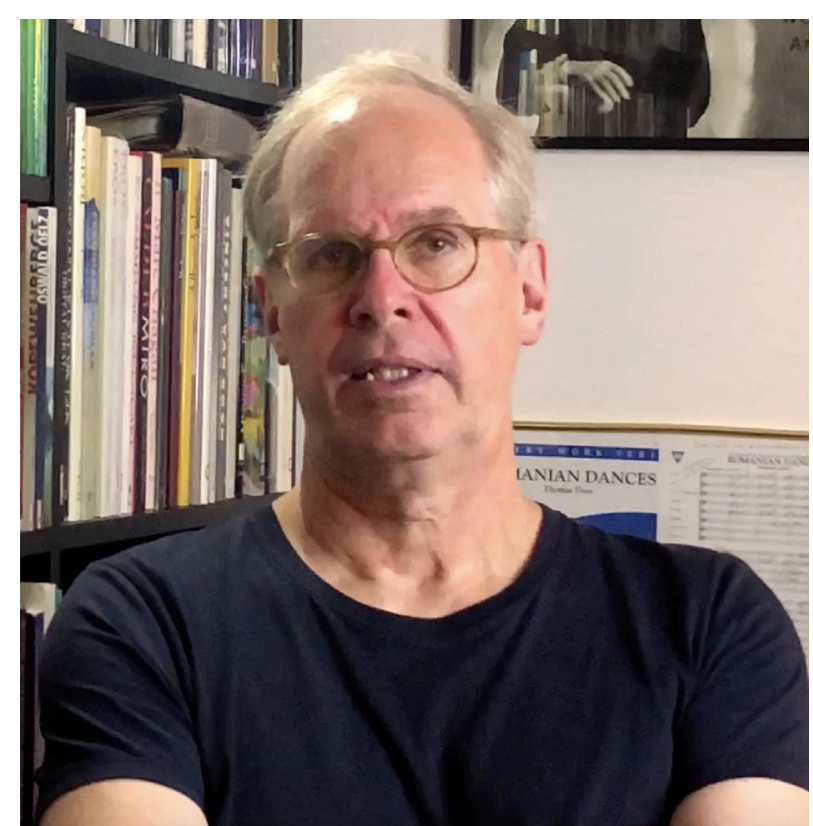

VIDEO 1. Why is this case report interesting? Video available at: https:// www.jtcvs.org/article/S0022-5223(19)31365-0/fulltext.

among them MitraClip (Abbott; Abbott Park, Ill), Cardioband (Edwards Lifesciences, Irvine, Calif), TriCinch, and transcatheter valved stents, orthotopic or heterotopic in the vena cava.

This report demonstrates (1) that transcatheter technologies rarely lead to perfect or durable results in patients with severe atrioventricular valve regurgitation and (2) that beating-heart cardiopulmonary bypass to perform tricuspid valve repair or replacement can be performed with a reasonable surgical risk in the majority of cases. In addition, early procedural results (the double Tri-Cinch was described as a success, even though the septolateral distance decreased only from 51 to $47 \mathrm{~mm}$ and the tricuspid regurgitation was still severe) from single transcatheter technology cases should be presented very cautiously, because technical feasibility sometimes merely describes technical procedural success only (eg, uncomplicated deployment of a new device) (Video 1). ${ }^{3}$

The initial TriCinch-in-TriCinch report was submitted only 3 months after the index procedure. At this time, there was a considerable residual tricuspid regurgitation and the symptoms had not significantly improved. ${ }^{2}$ New, apparently less invasive - and thus intriguing — technological innovations should not blind us to honest reporting, with careful and reasonable follow-up, with the aim of rationally assessing true benefits for the patients before these techniques are widely adopted.

\section{References}

1. Latib A, Agricola E, Pozzoli A, Denti P, Taramasso M, Spagnolo P, et al. First-inman implantation of a tricuspid annular remodeling device for functional tricuspid regurgitation. J Am Coll Cardiol Interv. 2015;8:e211-4.

2. Calen C, Taramasso M, Guidotti A, Kuwata S, Nietlispach F, Zuber M, et al. Successful TriCinch-in-TriCinch transcatheter tricuspid valve repair. J Am Coll Cardiol Interv. 2017;10:e75-7.

3. Carrel T, Eberle B, Pasic M. Cardioband to treat functional mitral regurgitation: a word of caution. Eur Heart J. 2019;40:490. 